\title{
Evaluation of Eco-environmental Quality of Coal Mining Area Using Multi-source Data - A Case Regarding Ibei Coalfield, Northwestern China
}

\section{Huan Jiang}

China University of Mining and Technology

Gangwei Fan ( $\square$ fangangwei@cumt.edu.cn )

China University of Mining and Technology

\section{Dongsheng Zhang}

China University of Mining and Technology

\section{Yibo Fan}

China University of Mining and Technology

\section{Research Article}

Keywords: Coalfields, Eco-environmental evaluation, Genetic projection pursuit model, Spatial autocorrelation, Driving factor

Posted Date: October 29th, 2021

DOI: https://doi.org/10.21203/rs.3.rs-998278/v1

License: (c) (i) This work is licensed under a Creative Commons Attribution 4.0 International License. Read Full License 


\section{Abstract}

Eco-environmental evaluation is a prerequisite for balancing the relationship between coal resource recovery and eco-environmental protection. This paper divides the eco-environment system in coal mining area into 5 subsystems regarding geomorphology, climate, hydrology, land and vegetation, and human activity. Within the 5 subsystems, 13 indicators capable of reflecting eco-environment levels of coal mine fields are selected, weighed using genetic projection pursuit model, and applied to eco-environmental quality evaluation. Based on this, the spatial feature of the quality is analysed using spatial autocorrelation method, recognising the areas that need managements. Factors driving the ecoenvironment characteristics of coal mines are identified using geographic detector. The feasibility of the developed evaluation system is verified with Ibei Coalfield as a case. The results show that Ibei Coalfield sees a spatially heterogeneous eco-environment pattern. Geographic detector can quantify the impact of various indicators on ecological environment, and the indicator is of stronger interpretation ability as interacting with others. It is also indicated that mining area eco-environment is nonlinearly correlated to impact indicators. The spatial autocorrelation analysis suggests three areas that should be treated strategically, that are the management area, close attention area and protective area. This paper can provide scientific references for mining area eco-environmental protection, which is significant for the sustainability of coal mine projects.

\section{Introduction}

Human activities are closely tied to ecology and environment. Understanding and assessing ecoenvironment level is not only an important research focus in the field of energy resource and environment, but also critically needed by sustainable economy and civilisation ${ }^{1}$. Coal is a key component of China's energy structure, accounting for $60 \%$ of the total annual energy consumption ${ }^{2}$. It has been identified that underground coal mining can lead to a series of problems such as surface subsidence, water level drawdown and vegetation deterioration, further affecting localised ecology and environment ${ }^{3,4}$. For achieving sustainable coal resource recovery, scientific evaluation of regional eco-environment level is significant, which is also conducive to guiding a rational pattern of energy resource utilisation and harmonising local economy and environment.

Eco-environmental quality evaluation (EEQE) refers to an evaluation on the whole ecological and environmental assembly or its some components of a selected area by selecting relevant factors such as geology, land resource, water resource, environment and economy within a designated temporal and spatial scope. Since 1950s when the concept "Ekistics" was proposed by Doxiadis, developed countries have started to quantitatively analyse and assess eco-environmental quality ${ }^{5,6}$. In several decades, study of EEQE mainly focused on developing evaluation indicator systems and evaluation methodologies ${ }^{7}$. An appropriate indicator system is the basis for achieving EEQE, in which the indicators can be selected from several aspects regarding natural features, infrastructures and social economy. EEQE methodologies include qualification and quantification aspects. Most studies are based on quantitative approaches that Loading [MathJax]/jax/output/CommonHTML/fonts/TeX/fontdata.js 
use equations or models to calculate selected indicators in community, economy and environment, and that the impact of human activity and natural environment on ecosystem variation can be assessed.

Frequently used quantitative evaluation approaches mainly include analytical hierarchy process ${ }^{8}$, fuzzy evaluation ${ }^{9}$, principal component analysis ${ }^{10}$, BP neural network ${ }^{11}$, support vector machine (SVM) model ${ }^{12}$, and set pair analysis ${ }^{13}$. Meanwhile, advances in computer technology facilitate the conversion from physical model to spatial analysis. Wan, et al. ${ }^{14}$ used RS and GIS techniques to construct an SD model considering community and ecology and analysed the development of Hadaqi Industrial Corridor. Based on remote sensing images, Fu, et al. ${ }^{15}$ assessed the coastal status of the Songhua River using spatial statistics. Based on RSEl model and RS technology, Jing, et al. ${ }^{16}$ evaluated the ecological environment quality of Aibi Lake Wetland Nature Reserve in Xinjiang,China. Although extensive studies have been conducted, there are still some limits in regional eco-environmental quality evaluation; External interference and data uncertainty lead to incomplete evaluation indicators, and subjectivisation and fuzzification in weighing indicators can affect the nonlinearity and non-normality of the indicator system.

Ibei Coalfield is one of the four largest coalfields in Xinjiang Province, China, but the only one that exists in oasis area ${ }^{17}$. It has been observed that underground coal deposits in Ibei Coalfield are of shallow depth, great thickness and simple geological conditions. Future large-scale mining activity may lead to a sequence of environmental problems, potentially threatening the stability of desert-oasis ecosystem. With Ibei Coalfield as a case, in this paper multi-source data from local geomorphology, climate, hydrogeology and human activity are analysed using genetic projection pursuit model, spatial autocorrelation and geographic detector to construct an EEQE system for coal mining area, and to develop a reasonable EEQE methodology that can provide guidance for mining activity management and potentially future mine design.

\section{Materials And Methods 2.1 Study area}

The case studied in this paper is from lli Kazak Autonomous Prefecture, Xinjiang Province, China. As shown in Figure 1, the area spans 31.1 50.0 km longitudinally and 5.6 11.1 km latitudinally, and the total coverage $450 \mathrm{~km}^{2}$ contains three subareas, the previously mined area of Ili No.4 Coal Mine, coal reserve area of Ili No.4 Coal Mine, and planned survey area of Ili No.5 Coal Mine. The case is located in the inner Eurasia, determining its temperate semi-arid continental climate where the annual average temperature is $10.4{ }^{\circ} \mathrm{C}$, precipitation is $368.5 \mathrm{~mm}$ and evaporation is $1500 \mathrm{~mm}$. Mount Tianshan is just on the east, giving rise to extremely uneven topography and deeply incised valleys. The maximum altitude difference of the area reaches $633 \mathrm{~m}$. Regional surface water is mainly valley streams formed from meltwater and seasonal rainfall.

\subsection{Data collection and processing}

Loading [MathJax]/jax/output/CommonHTML/fonts/TeX/fontdata.js

Page 3/29 
Table 1 lists the collected data. Before further spatial analysis, these original data are uniformly processed and projected onto WGS1984 coordinate system with ArcGIS software.

Table 1

Data collection and processing

\begin{tabular}{|c|c|c|}
\hline Data type & Data processing approaches & Source \\
\hline Terrain & Extraction or calculation using DEM data & Geospatial Data Cloud \\
\hline Landform & Cutting from vector map & $\begin{array}{l}\text { National Tibetan Plateau/Third Pole } \\
\text { Environment Data Centre }\end{array}$ \\
\hline Climate & $\begin{array}{l}\text { Interpolation of long-time average value } \\
\text { using Kriging }\end{array}$ & Yining Meteorological Bureau \\
\hline $\begin{array}{l}\text { River } \\
\text { system } \\
\text { distance }\end{array}$ & $\begin{array}{l}\text { Analysing river system by DEM data and } \\
\text { solving with Euclidean distance }\end{array}$ & Geospatial Data Cloud \\
\hline Vegetation & $\begin{array}{l}\text { Inversion of remote sensing satellite } \\
\text { imagery }\end{array}$ & Geospatial Data Cloud \\
\hline $\begin{array}{l}\text { Land } \\
\text { utilisation }\end{array}$ & $\begin{array}{l}\text { Interpretation of remote sensing satellite } \\
\text { imagery }\end{array}$ & Geospatial Data Cloud \\
\hline Population & Interpolation using Kriging & $\begin{array}{l}\text { Statistical Yearbook of Xinjiang } \\
\text { Uygur Autonomous Region }\end{array}$ \\
\hline Coal mines & Data spatialisation using ArcGIS & Field measurement \\
\hline
\end{tabular}

\subsection{EEQE system construction}

Figure 2 exhibits the procedures of constructing an EEQE system of mining area. Indicators that can reflect the eco-environment levels of coal mining area are selected and then weighed using genetic projection pursuit model. After evaluating and mapping regional ecological environment, the spatial autocorrelation and driving factors are analysed to guide localised environmental protection and mine design.

\subsubsection{Evaluation indicator selection}

Indicators for assessing eco-environment levels of a coal mine are rather complicated, and an appropriate selection is critical for EEQE. In accordance with the principle of evaluation indictor system construction and taking practicality and accessibility into account, 13 indicators are selected in regard to geomorphology, climate, hydrology, land resource, vegetation and human activity factors.

Geomorphology is closely related to hydrology, soil, vegetation and creature; its impact on ecological environment is characterised using elevation, terrain slope, terrain aspect and geomorphic type ${ }^{18}$. Annual average precipitation and evaporation determine localised climatic conditions, thus making it a nature

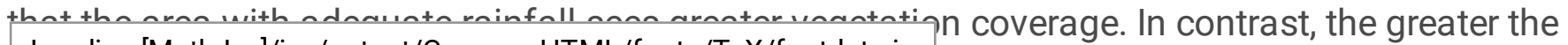
Loading [MathJax]/jax/output/CommonHTML/fonts/TeX/fontdata.js 
evaporation, the lower the moisture content of surface soils, possibly leading to water loss and land salinisation ${ }^{19}$. Shallow aquifer is a key hydrological factor underpinning ecosystem stability and characterised by specific yield; the greater the specific yield, the stronger the ability of an aquifer in water release ${ }^{20}$. River system distance represents the situation of surface waters, reflecting the impact of flows on surrounding soil erosion ${ }^{21}$ and on the circumstance of flora and fauna community ${ }^{22}$. As a factor affecting water and soil conservation as well as the stability of eco-system, vegetation coverage is represented via normalized differential vegetation index (NDVI) ${ }^{23}$. Also, land resource utilisation and layout are considered because of their eco-environmental impact; for example, regional ecology of the land for construction can be damaged to a great extent ${ }^{24}$.

Table 2

Positive external indicators of large-scale underground longwall mining

\begin{tabular}{|llll|}
\hline Indictors & Parameter & Indictors & Parameter \\
\hline Coal seam thickness & $\geq 3.5 \mathrm{~m}$ & Mine output & $500 \sim 1000 \mathrm{Mt} / \mathrm{a}$, or \\
& & & $\geq 1000 \mathrm{Mt} / \mathrm{a}$ \\
\hline Panel width & $\geq 200 \mathrm{~m}$ & Ratio of depth to thickness & $H / M<100$ \\
\hline Retreat rate & $\geq 5 \mathrm{~m} / \mathrm{d}$ & & \\
\hline
\end{tabular}

It is generally believed that the impact of underground coal mining on ecological environment is positively correlated to mining intensity ${ }^{25}$. The indicators representing mining intensity include positive external indicators (listed in Table 2) and negative external indicators ${ }^{26}$. The negative ones refer to the consequences resulting from coal seam extraction, which include overburden strata movement and ecoenvironmental damage. According to the classification standard, the previously mined area of Ili No.4 Coal Mine can be classified into high-intensity mining area. In contrast, the coal reserve area of Ili No.4 Coal Mine and the planned survey area of Ili No.5 Coal Mine should be unmined area. Within the whole area of the case, surface subsidence induced by coal exploitation can decrease available land resource, accelerate soil erosion, alter runoff and catchment conditions, and deteriorate ecological environment. Figure 3 shows the data map of the 13 indicators.

\subsubsection{Indicator weight determination}

The weight of 13 indicators is calculated using genetic projection pursuit model. For this purpose, high dimensional data are projected onto a lower dimensional space to construct objective functions and identify the best projection path capable of reflecting the structural feature of high dimensional data ${ }^{27,28}$. The basic procedures for projection pursuit modelling are as follows:

(1)Data standardisation 
The indicators are different in dimension and order of magnitude, which makes them lack comparability. So, the indictors are standardised by means of polarisation method in ArcGIS analytical tools. The processed indicators are between 0 and 1 .

(2)Projection indicator function construction

The sample set is $\{x(i, j) \mid i=1,2 \cdots, n ; j=1,2 \cdots, m\}$, where $m$ refers to the number of evaluation indicators and $n$ is the number of samples. The one-dimensional projection $(V i)$ of $m$ dimensional data along the direction $c=\{c(1), c(2), c(3), \cdots, c(m)\}$ is expressed as:

$V i=\sum_{j=1}^{m} c j \cdot x(i, j), i=1,2 \cdots, n$ (Eq. 1)

To meet two requirements that (i) local projection points should aggregate to the greatest extent and (ii) overall the projection should disperse as much as possible, a projection indicator function is established:

$Q(c)=S(c) \cdot D(c)($ Eq. 2)

$S(c)=\sqrt{\frac{\sum_{i=1}^{n}(V i-E(V i))^{2}}{n-1}}$ (Eq. 3)

$D(C)=\sum_{i=1}^{n} \sum_{j=1}^{n}[R-r i j] \cdot f[R-r i j]($ Eq. 4$)$

Where $S(c)$ is inter-class distance, $D(c)$ is within-class density, $E(V I)$ is the mean of $\{V i \mid i=1,2 \cdots, n\}$, rij is inter-sample distance and $r i j=|V i-V j|, R$ is the window radius of local density, and $f[R-r i j]$ is step function where if $R$ is greater than rij, $f[R-$ rij] equals 1 but if not, $f[R-r i j]$ equals $0 . D(c)$ represents the aggregation level of projection points; much greater the value of $D(C)$, more aggregated the points.

(3)Projection indicator function optimisation

Projection directions $(c)$ reflect the structural features of data. The maximised objective function and the corresponding constraint condition are expressed as:

$\operatorname{Max}: Q(c)=S(c) \cdot D(c)($ Eq. 5)

s. $t . \sum_{j=1}^{m} c j^{2}=1$ (Eq. 6)

Considering that the calculation of the best projection direction is a complicated nonlinear optimisation problem nenetir alanrithm is emnlnved to identifv the ontimal projection direction. 


\subsubsection{EEQE modelling}

Based on the optimal projection direction vector obtained above, the eco-environmental quality of coal mining area is quantified using mining area eco-environmental quality indicator (MAEEQI), in which the direction vector is as the weight of each evaluation indicator. Then the weighted summation of all indicators is calculated:

MAEEQI $=\sum_{i=1}^{n} w i \cdot u i=w 1 u 1+w 2 u 2+\cdots+w 2 u 2$ (Eq. 7)

$u i=c j^{2}$ (Eq. 8)

Where $u_{i}$ represents the weight of each indicator, $w_{i}$ is the standardised value of each indictor, and $\mathrm{n}$ is the number of evaluation indicators.

\subsubsection{Spatial autocorrelation}

As an approach to analyse the distribution characteristics of data, spatial autocorrelation is useful for testing the significance of an attribute value of variables and verifying the relevance of attributes between adjacent points. In this paper, spatial autocorrelation analysis is used to study the aggregation characteristics of the eco-environment conditions in Ibei Coalfield 29,30 .

(1)Global autocorrelation

Global autocorrelation characterises the aggregation and dispersion degree of eco-environmental quality within the whole space and expressed using Global Moran's / ranging between -1 and 1. There is:

$I=\frac{n \sum_{i=1}^{n} \sum_{j=1}^{n} w i j(x i-x)(x j-x)}{\sum_{i=1}^{n} \sum_{j=1}^{n} w i j(x i-x)^{2}}$ (Eq. 9)

Where $\mathrm{I}$ is the indictor of global autocorrelation, $\mathrm{n}$ is the total amount of elements, $x_{i}$ and $x_{j}$ are the eco-

environmental quality level of spatial unit $i$ and $j$ respectively, $x$ is the average value of eco-environmental quality, and $w_{i j}$ represents spatial weight coefficient matrix ${ }^{31}$.

(2)Local autocorrelation

Further, local spatial autocorrelation (expressed as Local Moran's I, ranging from -1 to 1) can be employed to analyse the aggregation and dispersion of eco-environmental quality in localised area. There is: 
$I p=\frac{n(x i-x) \sum_{j=1}^{n} w i j(x j-x)}{\sum_{i=1}^{n}(x i-x){ }^{2}}$ (Eq. 10)
2.3.5 Geographic detector

As a statistical method to analyse the spatial heterogeneity of data, geographic detector can identify the causality of different elements within a localised scale. The advantage is that this method can not only detect both quantitative and qualitative data, but also determine the interactive effect of two factors on dependent variable, even without any beforehand assumptions and constraint conditions ${ }^{32,33}$.

(1)Factor detection

Factor detection is employed to identify the spatial heterogeneity of eco-environmental quality in Ibei Coalfield and to analyse the impact degree of various indictor factors $(X)$ on eco-environmental quality $(Y)$. The result is measured using $q$ value, which can be expressed as:

$q=1-\frac{\sum_{h=1}^{L} N h \sigma h^{2}}{N \sigma^{2}}=1-\frac{S S W}{S S T}$ (Eq. 11)

Where $L$ is the layer of variable $Y$ or factor $X, N_{h}$ is the number of units in the $h^{\text {th }}$ layer, $N$ is the number of units in the whole area, $\sigma h^{2}$ is the variance of $Y$ in the $h^{\text {th }}$ layer, $\sigma^{2}$ is the variance of $Y$ in the whole area, and $S S W$ and $S S T$ represent the sum of variance of one layer and the whole area, respectively. Figure 4 shows the principle of factor detection.

(2) Interactive effect detection

Interactive effect can assess whether the cooperation of evaluation indicators $X_{1}$ and $X_{2}$ can enhance or weaken the interpretation of a single indictor on eco-environmental quality. $q$ that is corresponding to a single indictor is calculated, and so does q under the interaction of two indicators. Then comparisons are conducted among $q, q(X 1 \cap X 2)$ and sum of $q$, and the results are divided into five categories. The types of interactions are shown in Table 3. 
Table 3

Classification of interaction type

\begin{tabular}{|ll|}
\hline Criteria & Interaction type \\
\hline$q(X 1 \cap X 2)$ cript $>$ & Nonlinear attenuation \\
\hline$q(X 1 \cap X 2)>\max (q(X 1), q(X 2))$ & Bilinear enhancement \\
$\min (q(X 1), q(X 2))$ cript $>$ & Single-linear attenuation \\
\hline$q(X 1 \cap X 2)=q(X 1)+q(X 2)$ & Mutual independence \\
\hline$q(X 1 \cap X 2)>q(X 1)+q(X 2)$ & Nonlinear enhancement \\
\hline$(3)$ Risk detection & \\
\hline
\end{tabular}

Risk detection is to estimate whether the attribute mean value of two subareas have significant difference, expressed as $t$ statistics.

$$
\left.t(y h=1-y h=2)=\frac{Y h=1-Y h=2}{\left[\frac{\operatorname{Var}(Y h=1)}{n h=1}+\frac{\operatorname{Var}(Y h=2)}{n h=2}\right]}\right]^{1 / 2} \text { (Eq. 12) }
$$

Where $Y h$ is the attribute mean value of area $h$, is the number of samples in the area, and Var represents variance.

\section{Results}

\subsection{Evaluation indicator weight}

The calculation of indicator weight is achieved using Matlab programming, with total process including the optimisation solution of model via genetic algorithm and then cross iteration. The optimised direction vectors obtained via the above procedures are the weight of various indicators, as listed in Table 4. 
Table 4

Indicator weight

\begin{tabular}{|llll|}
\hline Indicators & Weights & Indicators & Weights \\
\hline Elevation $(\mathrm{X} 1)$ & 0.020 & River system distance (X8) & 0.086 \\
\hline Terrain slop (X2) & 0.027 & Land utilisation type (X9) & 0.072 \\
\hline Terrain aspect (X3) & 0.068 & NDVI (X10) & 0.084 \\
\hline Geomorphic type (X4) & 0.076 & Mining intensity (X11) & 0.089 \\
\hline Annual average precipitation (X5) & 0.125 & Population density (X12) & 0.070 \\
\hline Annual average evaporation $(X 6)$ & 0.076 & Surface subsidence (X13) & 0.121 \\
\hline Specific yield of aquifer (X7) & 0.076 & & \\
\hline
\end{tabular}

\subsection{Eco-environmental quality feature}

Based on the above calculated weights of 13 indicators, an EEQE model for Ibei Coalfield can be obtained:

$$
\begin{gathered}
\text { MEEQI }=\sum_{i=1}^{13} w i \cdot u i \\
=0.020 w 1+0.027 w 2+0.068 w 3+0.076 w 4+0.084 w 5+0.125 w 6+0.076 w 7 \\
+0.076 w 8+0.072 w 9+0.070 w 10+0.089 w 11+0.121 w 12+0.086 w 13
\end{gathered}
$$

For the mining area, its eco-environmental quality indicators are determined by Eq. 13. Further conformity and classification are successively conducted on the indicators using ArcGIS analytical tool, followed by visualisation of mining area eco-environmental quality indicator (MAEEQI) by combining Eq. 13 and weighted summation tool.

The standard adopted in this paper for eco-environmental quality evaluation and grading sources from Technical Criterion for Ecosystem Status Evaluation and currently existing research results ${ }^{34,35}$. The ecoenvironmental quality of study area is graded into five levels from worse to better by using natural break(Jenks), with results listed in Table 5.

Table 5

Mining area eco-environmental quality evaluation and grading

\begin{tabular}{|llllll|}
\hline Grade & Worse & Bad & Medium & Good & Better \\
\hline Numerical scope & $<0.501$ & $0.501 \sim 0.552$ & $0.552 \sim 0.606$ & $0.606 \sim 0.668$ & $>0.668$ \\
\hline
\end{tabular}

In Figure 5, the area with bad and worse eco-environmental quality accounts for $40.4 \%$ of the whole area, Loading [MathJax]/jax/output/CommonHTML/fonts/TeX/fontdata.js for 59.6\% (Table 6). Overall, the eco- 
environmental quality of Ibei Coalfield tends to be the medium level. Compared with Ili No. 4 Coal Mine area, Ili No.5 Coal Mine sees better situation, especially in the south and east of the planned survey area as there are sufficient rainfall, and greater vegetation coverage. In addition, No. 5 Coal Mine is still under planning, currently without high-intensity coal mining activity and strong engineering disturbance on the local ecology and environment. However, the middle area of Ili No. 5 Coal Mine exhibits bad to worse ecoenvironmental conditions because of urbanisation and human activity.

The overall eco-environmental quality of No. 4 Coal Mine is not as good as No .5 Coal Mine (Figure 6); worse area is up to $68.5 \%$ of the total No. 4 Coal Mine area, and good to better areas only account for $5.6 \%$. Up to now, the No. 4 Coal Mine has worked shallow longwall mining for many years, giving rise to a series of eco-environmental problems such as localised surface subsidence (Figures 7) and vegetation degradation. Despite conducting land and environmental treatment, mining impact is greater than the intrinsic eco-environmental bearing capacity and consequently, mining-induced damage is faster than ecological rehabilitation.

In the coal reserve area of Ili No.4 Coal Mine, about $51.1 \%$ of the area is graded into medium to better, suggesting a critical state. In this area low-altitude hilly topography prevails, with large population density, scattered grasslands and low vegetation coverage. Environmental treatment and appropriate mine arrangement have been scheduled but still in the initial stage. Some infrastructural project for future underground mining activity leads to eco-environment deterioration, which should be a focus for the follow-up engineering operations.

Table 6

Statistical area and proportion of each grade

\begin{tabular}{|lll|}
\hline Grades & Area $\left(\mathrm{Km}^{2}\right)$ & Proportion (\%) \\
\hline Worse & 66.56 & 12.3 \\
\hline Bad & 151.98 & 28.1 \\
\hline Medium & 165.66 & 30.7 \\
\hline Good & 98.82 & 18.3 \\
\hline Better & 54.58 & 10.6 \\
\hline
\end{tabular}

\subsection{Spatial pattern of eco-environmental quality}

Under the premise that the scale information is complete and evaluation result is accurate, the ecoenvironment feature of study area is graphically resampled using $500 \times 500 \mathrm{~m}$ square meshes, totally outputting 2294 sampling points. Then the spatial autocorrelation of eco-environmental quality is 
(Figure 8) and LISA index spatial aggregation diagram (Figure 9). The calculation shows that the Moran's I of Ibei Coalfield equals 0.865 , suggesting a significantly positive correlation in eco-environmental quality and distinguished spatial aggregation phenomenon, and that the area with low eco-environmental quality can impact the adjacent area.

In Figure 9 most data points are scattered along the regression line, featuring an eco-environmental quality pattern that homogeneity aggregates and heterogeneity disperses. By combining the spatial adjacency characteristics, it can be seen that two quadrants $\mathrm{H}-\mathrm{H}$ and L-L exhibit spatial heterogeneity; in $\mathrm{H}-\mathrm{H}$ and $\mathrm{L}-\mathrm{L}$ the data points are concentrated, indicating that the area with high eco-environmental quality and area with low quality aggregate separately and show a significantly positive correlation. Differently, in quadrants $\mathrm{H}-\mathrm{L}$ and $\mathrm{L}-\mathrm{H}$ the data points are rather lesser and scattered and witness negative correlation, indicating that high eco-environmental quality area and low quality area are surrounded mutually.

It is analysed from Figure 9 that $\mathrm{H}-\mathrm{H}$ aggregation takes 574 spatial units in the southwest of the coal reserve area of Ili No.4 Coal Mine, southwest and east of Ili No. 5 Coal Mine. L-L aggregation takes 661 spatial units mainly in the previously mined area of Ili No.4 Coal Mine and partial area of the coal reserve area of Ili No.4 Coal Mine, and further coal mining activity can deteriorate ecology and environment of these two areas. Meanwhile, eco-environmental quality outliers have occurred in some area, which is represented by $\mathrm{H}-\mathrm{L}$ outliers. The outliers are mainly the grassland and/or forest surrounded by construction land and/or desert, which makes them exhibit higher quality than their surrounding areas. L$\mathrm{H}$ aggregation only takes 1 spatial unit, thus showing weak autocorrelation and random distribution.

\subsection{Eco-environmental driving factors}

Geographic detector model requires independent variables to be type data, so the zoning grades and zoning methods are likely to affect detection results. To decrease errors, various indicators are zoned using natural discontinuity point method, giving rise to 9 types in terms of surface elevation, terrain slope, terrain aspect, NDVI, annual average precipitation, annual average evaporation, aquifer specific yield, population density and river system distance, 6 types for land utilisation, and 2 types for mining intensity, surface subsidence and landforms.

\subsubsection{Driving factor detection and analysis}

Figure 10 shows the eco-environmental factors detected in Ibei Coalfield. $q$ value can reflect the difference of various indicators in driving local ecology and environment. Mining intensity(X11) ranks the first in terms of the interpretation ability, followed by annual average precipitation(X5), surface elevation(X1), annual average evaporation(X6), NDVI(X10), land utilisation type(X9), surface subsidence $(X 13)$, population density $(X 12)$, terrain slope $(X 2)$, terrain aspect $(X 3)$, aquifer specific yield( $X 7)$, river system distance(X8) and landform type(X9). The current eco-environmental quality in lbei Coalfield results from the interaction of natural conditions and human activities. If checking the interpretation ability, mining intensity is the primary factor driving the change of eco-environment level, with 
average evaporation are higher than $20 \%$, and NDVI, surface subsidence and land utilisation type are higher than $10 \%$. Other indicators are of relatively weaker ability in interpretation. Aquifer specific yield, river system distance and landform type have high $P$ values, thus showing non-significant impact.

\subsubsection{Indicator interaction analysis}

The results of interaction detection are shown in Figure 11. It can be seen from Figure 11 that the interaction of terrain, climate, hydrology, land utilisation, vegetation coverage and human activity is stronger than any single factor among them, suggesting that various factors are closely related and interactively affect coal mine eco-environmental quality. The interactive effect of various indicators on eco-environmental quality includes two forms, linear enhancement and nonlinear enhancement, and the forms account for $35.9 \%$ and $64.1 \%$ respectively. In detail, the combination of mining intensity and other indicators has stronger interpretation ability; X11 XX10 (mining intensity and NDVI) shows the highest interpretation ability $(q=0.655)$, indicating that mining activity enhances the interpretation ability of NDVI as the single independent variable. The interaction of mining intensity (X11) with indicators including NDVI (X10), terrain slope (X2), annual average evaporation (X6) and land utilisation (X9) sees nonlinear enhancement effect, whereas sees linear enhancement with other indicators. In addition to mining intensity, the interaction of terrain slope (X2), annual average precipitation (X5) and annual average evaporation (X6) with other indicators also enhances their ability in interpreting the eco-environmental quality of study area. Overall, the interactive effect of various factors on eco-environmental quality cannot be considered a simple superposition, but a linear and/or nonlinear enhancement.

\subsubsection{Impact of linearity and nonlinearity of indicators}

Risk detection can reflect the linear and nonlinear variation of mining area ecology and environment with a specific indicator. As shown in Figure 12, the eco-environmental quality changes linearly with the zoning grades of geomorphology, mining intensity and surface subsidence, but nonlinearly with other indicators.

Surface elevation and terrain slope share similar nonlinear characteristics; with the increase of zoning grades, mine eco-environmental quality experiences a decrease-increase process, as shown in Figure 12 (a) and (b). In terms of terrain aspect, the less sunny side of a slope tends to show higher ecoenvironmental quality because of lesser evaporation and stronger ability to retain moisture, as shown in Figure 12 (c). Figure 12 (e), (g) and (j) show wavelike increases in eco-environmental quality with annual average precipitation, aquifer specific yield and NDVI, indicating that sufficient rainfall, shallow water resource and high vegetation coverage are conducive to the development of ecology and environment. Annual average evaporation and population density show negative effect, indicated by Figure $12(f)$ and (l). Also, Figure $12(\mathrm{~h})$ and (i) exhibit that eco-environmental quality is closely related to river system distance and land utilisation pattern; when the area is 458.9 to $618.4 \mathrm{~m}$ away from a river and used as forestry land, it shows higher eco-environmental quality.

\section{Discussion}




\subsection{Spatial pattern and driving factors of eco-environmental quality}

This paper uses genetic projection pursuit model, spatial autocorrelation and geographic detector to develop a method to evaluate the eco-environmental quality of coal mining area, further analysing the spatial structure and driving factors of eco-environmental quality with Ibei Coalfield as a case.

In terms of the spatial pattern, the previously mined area of Ili No. 4 Coal Mine possesses worser ecoenvironmental quality, and the coal reserve area is in a critical state, compared with which the No. 5 Coal Mine is much better because of being in a planning stage. In the whole study area, surface elevation, annual average precipitation and NDVI show a gradient descent from east to west, while annual average evaporation and aquifer specific yield increase from east to west. The inhomogeneous distribution of these geomorphological, climatic and hydrological indicators should be the primary cause of the spatial heterogeneity of eco-environmental quality.

In terms of the driving mechanism of various factors, the natural ones are of significant impact on localised eco-environment levels. The ability of surface elevation, annual average precipitation and annual average evaporation to interpret eco-environmental quality is $26.3 \%, 27.2 \%$ and $20.6 \%$ respectively. In general, high elevation region tends to be cold, topographically fluctuated and low soil quality, which has great impact on the local ecology and environment. However, in this study, ecoenvironmental quality enhances with elevation. It is speculated that high elevation regions experience less disturbance from human activities such as underground coal mining and construction projects. In addition, there can be a threshold for the elevation impact on ecological environment ${ }^{33}$; the case area does not reach the threshold considering that it is not in an extremely high elevation region. Ibei Coalfield is in the northwest inland of China and less affected by monsoon, featuring a greater evaporation than precipitation. Due to the nature that ecology and environment are relatively sensitive to rainfall ${ }^{1}$, annual average precipitation has stronger interpretation ability than annual average evaporation. Compared with others, mining intensity is the most primary factor driving the change of eco-environment level in coal mining area, with q value reaching $34.8 \%$, which also agrees with the results obtained by Yang, et al. ${ }^{36}$. Overall, high-intensity coal mining projects can lead to serious damage to the overlying ecology and environment, also directly accounting for the spatial heterogeneity of eco-environmental quality. Based on this, natural and human factors interact, resulting in further eco-environment degradation.

\subsection{Mining area eco-environment management strategy}

The above conducted spatial autocorrelation analysis helps to identify the region that needs to be managed, and the geographic detector analysis indicates the factors driving the change of ecoenvironment. By combining the two analyses, an appropriate strategy for coal mining area ecoenvironment management is developed. 
The low eco-environmental quality area $(\mathrm{L}-\mathrm{L})$ is classified as the management area, requiring multi-layer and intensive treatments such as ecological rehabilitation. The government should design the corresponding protective strategies to motivate and compensate the coal mines implementing ecoenvironmental protection policies ${ }^{37}$. Also, coal enterprises should control the intensity of land utilisation and building density, and strengthen green infrastructure design by, for example, filling topsoil cracks and growing special plants with drought tolerance and developed roots to prevent water and soil erosion. In addition, the core of scientific mining is to control the level of subsurface water since damaged plants and soil can restore in a short term by implementing land rehabilitation, whereas declined water level may need longer period to recover ${ }^{38}$. Water level control can be achieved by adjusting mining parameters; for example, limiting mining height is effective in preventing mining-induced fractures from reaching the shallow aquifer. Similarly, protective mining measures are also available, such as filling mining 39,40 and slice mining ${ }^{41}$.

$\mathrm{H}-\mathrm{H}$ area has better eco-environmental quality. Considering that the future coal mining activity is likely to bring about localised deterioration, $\mathrm{H}-\mathrm{H}$ area is classified into close attention area. On the one hand, coal enterprises should consider the eco-environment situation and combine " $3 \mathrm{~S}$ " technique to construct an eco-environmental database and update by conducting continuous field measurement. On the other hand, new mines can take references from adjacent ones in production, implement appropriate premining design, and strengthen technical innovation over eco-environmental management.

Anomalous areas $\mathrm{L}-\mathrm{H}$ and $\mathrm{H}-\mathrm{L}$ can be used to predict and prevent eco-environmental risks as the localised low quality may propagate to the surrounding under the effect of spatial polarisation. So the areas labelled with $\mathrm{L}-\mathrm{H}$ and $\mathrm{H}-\mathrm{L}$ are classified into protective area. In protective areas it is necessary to designate a warning line for eco-environmental protection, in which it is required to preserve the grassland and forest, control urbanisation rate and optimise land utilisation patter. Also, the above designed policies are accompanied by financial supports from the local government so as to construct an accountability strategy with the cooperation of government and coal enterprises.

\subsection{Strength and limits}

By adopting projection pursuit model, the paper analyses the data with high dimension, nonlinearity and nonnormal index to identify the optimal projection direction, which effectively solves the problem regarding complicated structures and features of high dimensional data in nonlinear system. Compared with the conventional approaches like AHP, fuzzy comprehensive evaluation and PCA, this method copes with data more objectively and avoids subjective factors ${ }^{42}$ and masses of missing pieces, by which objective results can be obtained. Further, geographic detector method is of significant strength in analysing the driving factors of eco-environmental quality variation; it can not only quantify the interaction within a single indicator and between various indicators, but also reflect the nonlinear relationship between indicators and results if compared with conventional statistical analyses. In addition, the MAEEQE method developed in this paper can be relatively flexible in designing evaluation pronodurac and colontinn avaluation indinatare Tho M $\triangle E E Q E$ method can provide strategic guidance for Loading [MathJax]/jax/output/CommonHTML/fonts/TeX/fontdata.js 
ecological protection and environment management, allowing managers to conduct reasonable premining design and post-mining rehabilitation.

The research also has some limits. For evaluation indicator and model selection, it is unavoidable to be impacted by noisy data and data incompleteness; for example, it is pointed out that soil pattern can also affect localised ecological environment to some extent 43,44 , which is not included into in this paper considering the difficulty in relevant data gathering. In addition, the evaluation on some systems, especially the terrestrial ecosystem, mainly takes normalized differential vegetation index (NDVI) and dominant plant community as the representative indicator, possibly lacking the indicators capable of reflecting the dynamic variation of a community, such as population competition. At present, identifying indicators that represent the dynamic process of eco-environmental quality fluctuation and its tendency is still a key problem.

\section{Conclusion}

The paper extracts 13 indicators capable of reflecting the eco-environmental quality of coal mining area from 5 factors including surface geomorphology, climate, hydrology, land resource and vegetation, and human activity, further analysing the eco-environmental quality of Ibei Coalfield by adopting genetic projection pursuit model and mining area eco-environmental quality evaluation model. Based on this, the spatial structure and driving factors are studied by means of spatial autocorrelation and geographic detector.

The eco-environmental quality of Ibei Coalfield is graded into worse, bad, medium, good and better levels, and the overall quality level tends to be medium. Compared with the previously mined area (lli No. 4 Coal Mine), unmined areas exhibit higher eco-environmental quality. The results of geographic detector analysis indicate that both natural and human factors have significant impact on the quality, among which mining intensity as one of the human factors shows the strongest ability to interpret ecoenvironmental quality situation. The impact of two interactive indictors is greater than that of a single indictor, and there is a nonlinear relationship between indictors and the responsive eco-environment level. Spatial autocorrelation analysis shows that Moran's I of the whole study area equals 0.865 ; ecoenvironment represents positive correlation and is of significant concentration and spatial heterogeneity feature. With the H-H, L-L, H-L and L-H in LISA aggregation diagram as references, three areas were designated including management area, close attention area and protective area, for which three different strategies are designed considering the results of spatial autocorrelation and driving factor analysis. This study provides a possible method for quantifying the ecological environment in the mining area and quantifying the driving forces of the ecological environment in the mining area, which is of great importance for the coordinated development of coal mining and the ecological environment.

\section{Declarations}


The authors declare that they have no conflicts of interest.

\section{Funding statement}

This work was financially supported by the National Natural Science Foundation [grant number 51974291], Fundamental Research Funds for the Central Universities [grant number 2021ZDPY0226], Shanxi Province Unveils Bidding Project [grant number 20201101009], the Assistance Program for Future Outstanding Talents of China University of Mining and Technology [grant number 2020WLJCRCZL092] and the Postgraduate Research \& Practice Innovation Program of Jiangsu Province.

\section{Acknowledgments}

The author thanks Ili No. 4 Mine for its support and Dr. Mingwei Chen for his guidance on the writing framework, as well as the helpful comments provided by the anonymous reviewers.

\section{References}

1. Cui, E., Ren, L. \& Sun, H. Evaluation of variations and affecting factors of eco-environmental quality during urbanization. Environ Sci Pollut Res Int, 22, 3958-3968 https://doi.org/10.1007/s11356-0143779-6 (2015).

2. Wang, Q. \& Song, X. Why do China and India burn $60 \%$ of the world's coal? A decomposition analysis from a global perspective. Energy, 227, https://doi.org/10.1016/j.energy.2021.120389 (2021).

3. Kuz'Min, M. I., Kuznetsova, A. N., ECOLOGICAL-GEOLOGIC RISKS RELATED TO \& THE DEVELOPMENT OF RESOURCE REGIONS. Geography and Natural Resources, 5-13 https://doi.org/10.21782/gipr0206-1619-2018-2(5-13 (2018).

4. Wang, G. C., Du, H. \& Inc, D. E. P. in International Conference on Industrial Engineering and Management Science (ICIEMS). 927-935(2013).

5. Mukherjee, M., Ray, A. K. \& Rajyalakshmi, C. Physical quality of life index: Some international and Indian applications. Soc. Indic. Res, 6, 283-292 https://doi.org/10.1007/BF00300651 (1979).

6. Pacione, M. Urban environmental quality and human wellbeing-a social geographical perspective. Landscape and Urban Planning, 65, 19-30 https://doi.org/10.1016/s0169-2046(02)00234-7 (2003).

7. Wen, J. \& Hou, K. Research on the progress of regional ecological security evaluation and optimization of its common limitations. Ecol. Ind, 127, https://doi.org/10.1016/j.ecolind.2021.107797 (2021).

8. Cao, D. Y., Huang, C. L., Wu, J., Li, H. T. \& Zhang, Y. D. Environment Carrying Capacity Evaluation of Coal Mining in Shanxi Province. Adv. Mater. Res, 518-523, 1141-1144 https://doi.org/10.4028/www.scientific.net/AMR.518-523.1141 (2012). 
9. Chen, J., Ma, L. \& Zhang, H. A new method for mining area ecological environment assessment based on credibility measure. Kybernetes, 42, 55-66 https://doi.org/10.1108/03684921311295475 (2013).

10. Keshavarzi, A. \& Kumar, V. Ecological risk assessment and source apportionment of heavy metal contamination in agricultural soils of Northeastern Iran. Int J Environ Health Res, 29, 544-560 https://doi.org/10.1080/09603123.2018.1555638 (2019).

11. Zhao, K. et al. Application Research of Artificial Neural Network in Environmental Quality Monitoring. International Journal of Pattern Recognition and Artificial Intelligence, 33, https://doi.org/10.1142/s0218001419590390 (2019).

12. Wang, Y., Wu, X., He, S. \& Niu, R. Eco-environmental assessment model of the mining area in Gongyi, China. Sci Rep, 11, 17549 https://doi.org/10.1038/s41598-021-96625-9 (2021).

13. He, G. et al. Assessment of ecological vulnerability of resource-based cities based on entropy-set pair analysis. Environ Technol, 42, 1874-1884 https://doi.org/10.1080/09593330.2019.1683611 (2021).

14. Wan, L. et al. A study of regional sustainable development based on GIS/RS and SD model - Case of Hadaqi industrial corridor. Journal of Cleaner Production, 142, 654-662 https://doi.org/10.1016/j.jclepro.2016.09.086 (2017).

15. Fu, B. et al. Evaluation of riparian condition of Songhua River by integration of remote sensing and field measurements. Sci Rep, 7, 2565 https://doi.org/10.1038/s41598-017-02772-3 (2017).

16. Jing, Y. et al. Assessment of spatial and temporal variation of ecological environment quality in Ebinur Lake Wetland National Nature Reserve, Xinjiang, China. Ecol. Ind, 110, https://doi.org/10.1016/j.ecolind.2019.105874 (2020).

17. Xu, Y. J. et al. Vegetation patterns and ecological factors in the lli River Valley, Xinjiang, China. Nordic Journal of Botany, 29, 87-96 https://doi.org/10.1111/j.1756-1051.2010.00868.x (2011).

18. Lopez, N., Spizzico, V. \& Parise, M. Geomorphological, pedological, and hydrological characteristics of karst lakes at Conversano (Apulia, southern Italy) as a basis for environmental protection. Environ. Geol, 58, 327-337 https://doi.org/10.1007/s00254-008-1601-9 (2009).

19. Pan, F., Tian, C., Shao, F., Zhou, W. \& Chen, F. Evaluation of ecological sensitivity in Karamay, Xinjiang, China. Journal of Geographical Sciences, 22, 329-345 https://doi.org/10.1007/s11442-012-0930-5 (2012).

20. Lv, M., Xu, Z., Yang, Z. L., Lu, H. \& Lv, M. A. Comprehensive Review of Specific Yield in Land Surface and Groundwater Studies. Journal of Advances in Modeling Earth Systems, 13, https://doi.org/10.1029/2020ms002270 (2021).

21. Lin, J., Chen, W., Qi, X. \& Hou, H. Risk assessment and its influencing factors analysis of geological hazards in typical mountain environment. Journal of Cleaner Production, 309, https://doi.org/10.1016/j.jclepro.2021.127077 (2021).

22. Ward, J. V., Tockner, K., Arscott, D. B. \& Claret, C. Riverine landscape diversity. Freshw. Biol, 47, 517539 https://doi.org/10.1046/j.1365-2427.2002.00893.x (2002). 
23. Mind'je, R. et al. Flood susceptibility modeling and hazard perception in Rwanda. International Journal of Disaster Risk Reduction, 38, https://doi.org/10.1016/j.ijdrr.2019.101211 (2019).

24. Jia, X. L., Wang, D., Liu, F. B., Dai, Q. M. \& EVALUATION OF HIGHWAY CONSTRUCTION IMPACT ON ECOLOGICAL ENVIRONMENT OF QINGHAI-TIBET PLATEAU. Environmental Engineering and Management Journal, 19, 1157-1166 (2020).

25. Xiao, W., Zhang, W., Ye, Y., Lv, X. \& Yang, W. Is underground coal mining causing land degradation and significantly damaging ecosystems in semi-arid areas? A study from an Ecological Capital perspective. Land Degradation \& Development, 31, 1969-1989 https://doi.org/10.1002/ldr.3570 (2020).

26. Guo, W., Zhao, G., Lou, G. \& Wang, S. A. New Method of Predicting the Height of the Fractured WaterConducting Zone Due to High-Intensity Longwall Coal Mining in China. Rock Mechanics and Rock Engineering, 52, 2789-2802 https://doi.org/10.1007/s00603-018-1567-1 (2018).

27. da Silva, N., Cook, D. \& Lee, E. K. A Projection Pursuit Forest Algorithm for Supervised Classification. Journal of Computational and Graphical Statistics, doi:10.1080/10618600.2020.1870480.

28. Espezua, S., Villanueva, E. \& Maciel, C. D. Towards an efficient genetic algorithm optimizer for sequential projection pursuit. Neurocomputing, 123, 40-48 https://doi.org/10.1016/j.neucom.2012.09.045 (2014).

29. Dormann, C. F. et al. Methods to account for spatial autocorrelation in the analysis of species distributional data: a review., 30, 609-628 https://doi.org/10.1111/j.2007.0906-7590.05171.x (2007).

30. Shaikh, S. F. E. A. et al. Accounting for spatial autocorrelation is needed to avoid misidentifying tradeoffs and bundles among ecosystem services. Ecol. Ind, 129, https://doi.org/10.1016/j.ecolind.2021.107992 (2021).

31. Xiong, Y. et al. Assessment of spatial-temporal changes of ecological environment quality based on RSEl and GEE: A case study in Erhai Lake Basin, Yunnan province, China. Ecol. Ind, 125, https://doi.org/10.1016/j.ecolind.2021.107518 (2021).

32. Chen, T., Feng, Z., Zhao, H. \& Wu, K. Identification of ecosystem service bundles and driving factors in Beijing and its surrounding areas. Science of the Total Environment, 711, https://doi.org/10.1016/j.scitotenv.2019.134687 (2020).

33. Zhu, L., Meng, J. \& Zhu, L. Applying Geodetector to disentangle the contributions of natural and anthropogenic factors to NDVI variations in the middle reaches of the Heihe River Basin. Ecol. Ind, 117, https://doi.org/10.1016/j.ecolind.2020.106545 (2020).

34. Chang, Y., Hou, K., Wu, Y., Li, X. \& Zhang, J. A conceptual framework for establishing the index system of ecological environment evaluation-A case study of the upper Hanjiang River, China. Ecol. Ind, 107, https://doi.org/10.1016/j.ecolind.2019.105568 (2019).

35. He, F., Gu, L., Wang, T. \& Zhang, Z. The synthetic geo-ecological environmental evaluation of a ta: A case study in Longkou, China. Journal of 
Cleaner Production, 142, 854-866 https://doi.org/10.1016/j.jclepro.2016.07.011 (2017).

36. Yang, Z., Li, W., Li, X., Wang, Q. \& He, J. Assessment of eco-geo-environment quality using multivariate data: A case study in a coal mining area of Western China. Ecol. Ind, 107, https://doi.org/10.1016/j.ecolind.2019.105651 (2019).

37. Xi, B. \& Jing, H. Research on horizontal compensation of ecological economic benefits under differential responsibility. Environmental Science and Pollution Research, 28, 29875-29889 https://doi.org/10.1007/s11356-021-12835-8 (2021).

38. Forkel, C., Hassel, S., Rinaldi, P. \& Mueller, C. Future groundwater rise in the Rhenish lignite area and related tasks. Wasserwirtschaft, 107, 12-19 https://doi.org/10.1007/s35147-017-0027-2 (2017).

39. Ma, D. et al. Reutilization of gangue wastes in underground backfilling mining: Overburden aquifer protection., 264, $128400 \mathrm{https} / / /$ doi.org/10.1016/j.chemosphere.2020.128400 (2021).

40. Wang, X. F., Zhang, D. S., Sun, C. D. \& Wang, Y. Surface subsidence control during bag filling mining of super high-water content material in the Handan mining area. International Journal of Oil Gas and Coal Technology, 13, 87-102 https://doi.org/10.1504/ijogct.2016.078049 (2016).

41. Guo, W., Tan, Y. \& Bai, E. Top coal caving mining technique in thick coal seam beneath the earth dam. International Journal of Mining Science and Technology, 27, 165-170 https://doi.org/10.1016/j.ijmst.2016.11.005 (2017).

42. Shao, $\mathrm{H}$. et al. A method to the impact assessment of the returning grazing land to grassland project on regional eco-environmental vulnerability. Environ. Impact Assess. Rev, 56, 155-167 https://doi.org/10.1016/j.eiar.2015.10.006 (2016).

43. Jones, M. M. et al. Explaining variation in tropical plant community composition: influence of environmental and spatial data quality., 155, 593-604 https://doi.org/10.1007/s00442-007-0923-8 (2008).

44. Wang, Y., Shao, M. \& Liu, Z. Large-scale spatial variability of dried soil layers and related factors across the entire Loess Plateau of China., 159, 99-108 https://doi.org/10.1016/j.geoderma.2010.07.001 (2010).

\section{Figures}




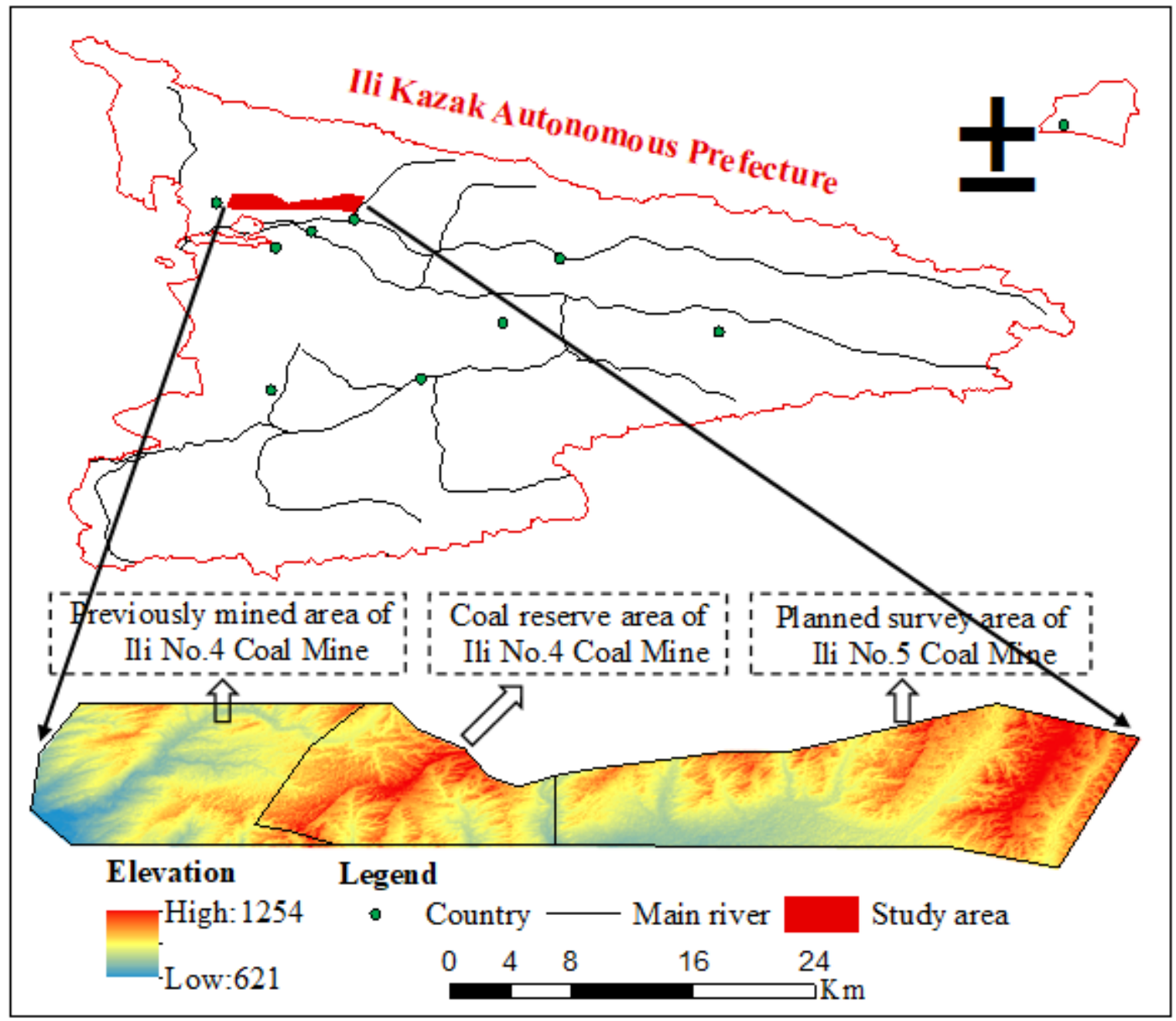

Figure 1

Location and elevation of the study area 


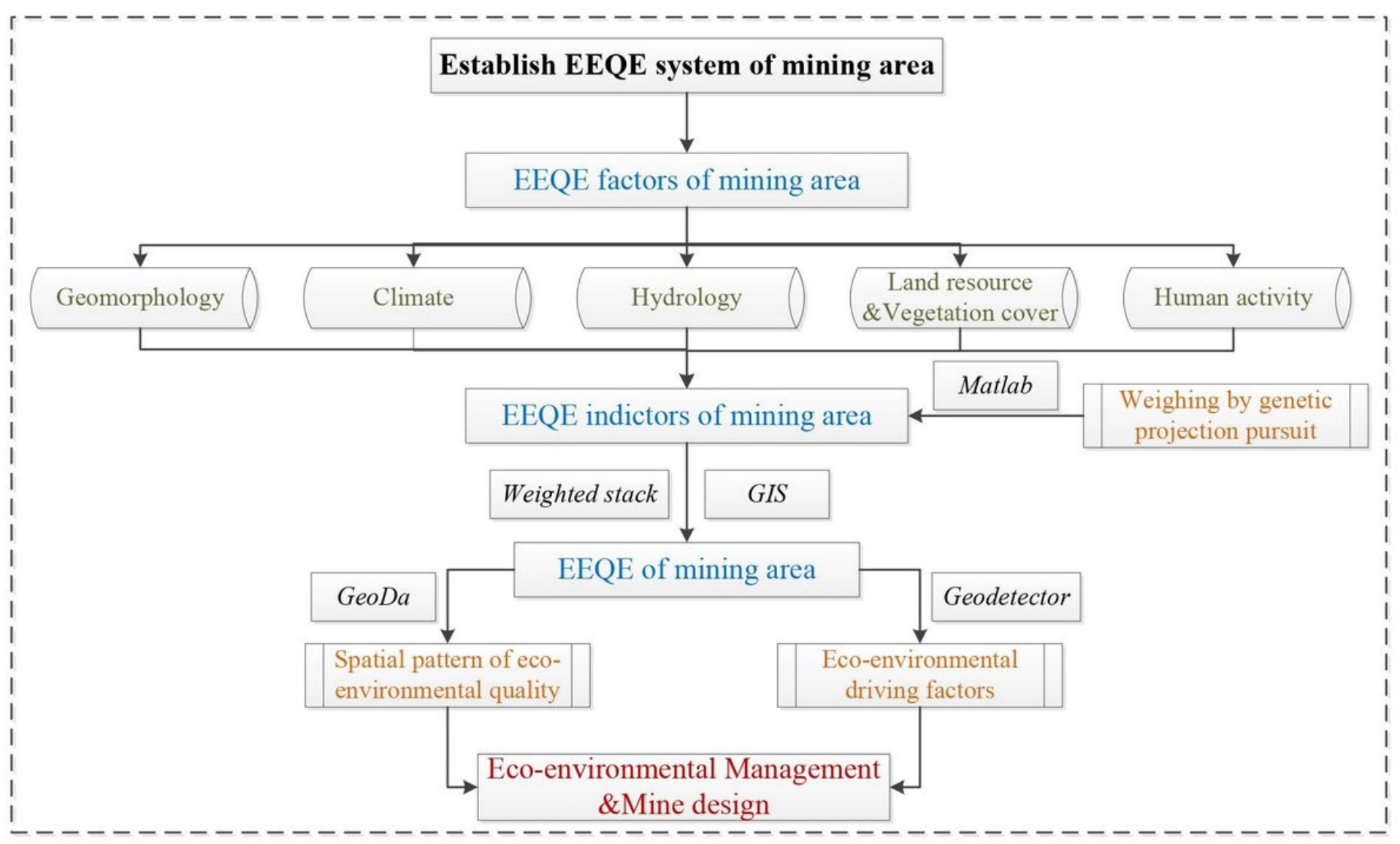

\section{Figure 2}

Research framework 

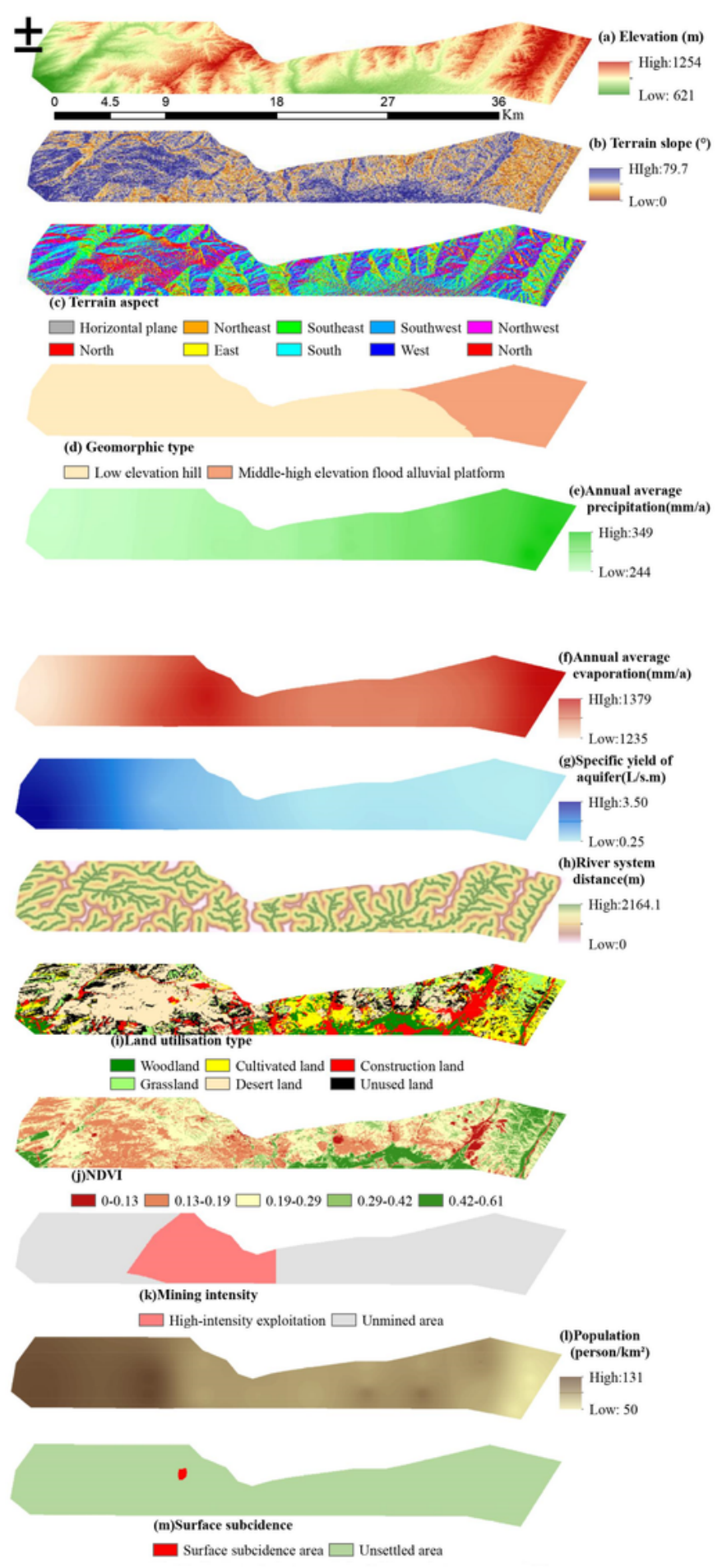

\section{Figure 3}

Eco-environmental quality evaluation indicators 


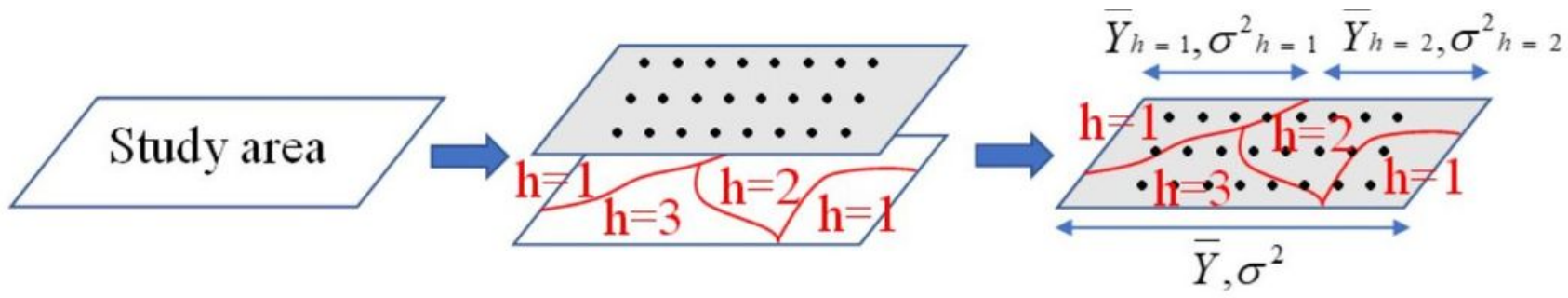

Figure 4

Fundamentals of factor detection

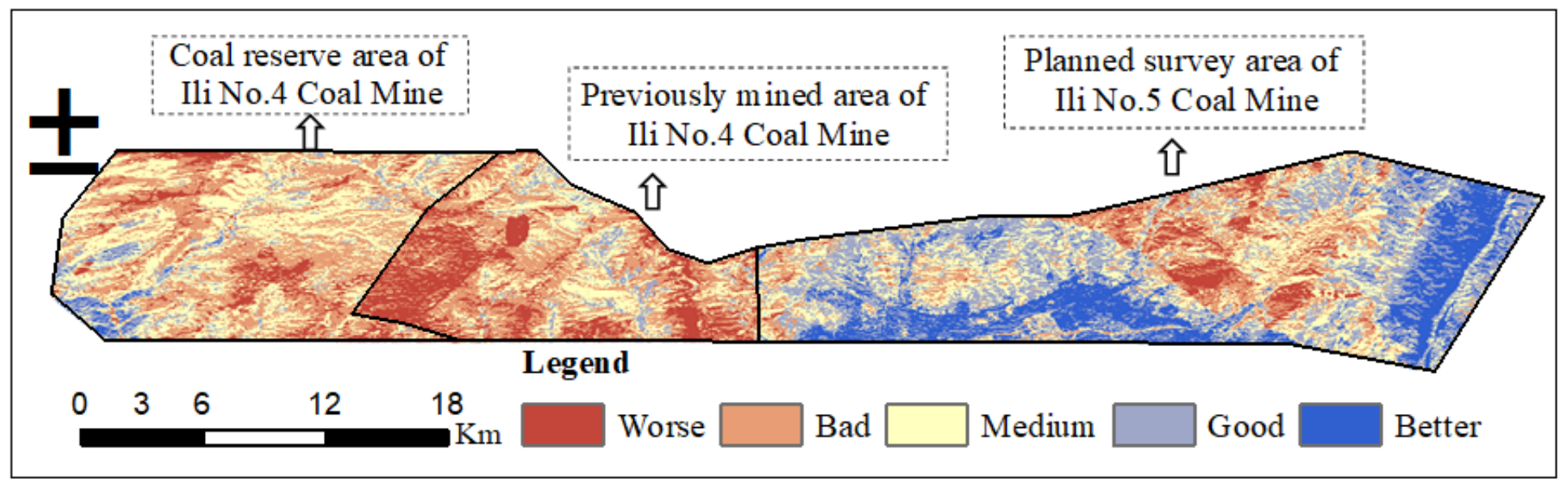

Figure 5

Eco-environmental quality evaluation and grading
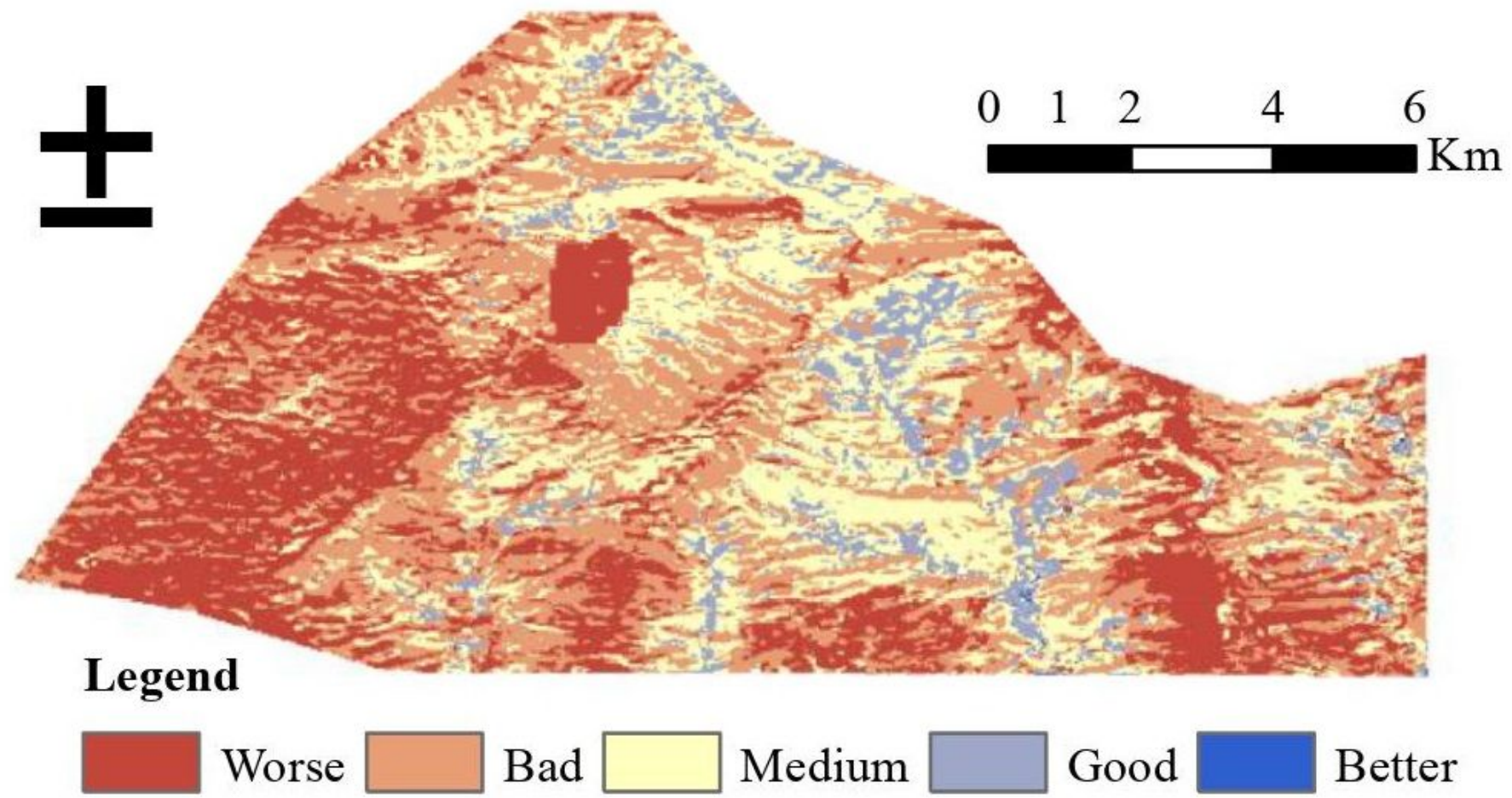


\section{Figure 6}

Eco-environmental quality grading for lli No. 4 Coal Mine

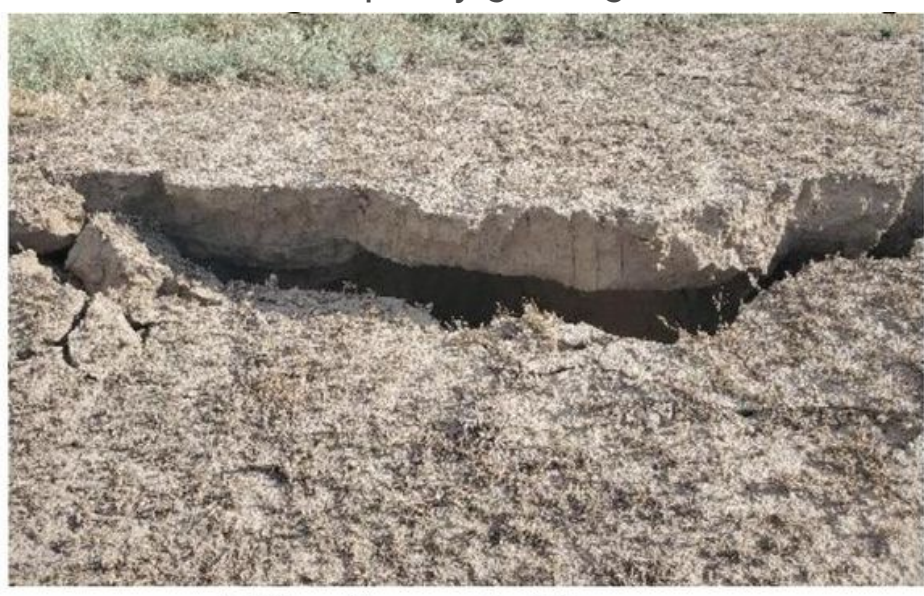

(a)Surface subsidence

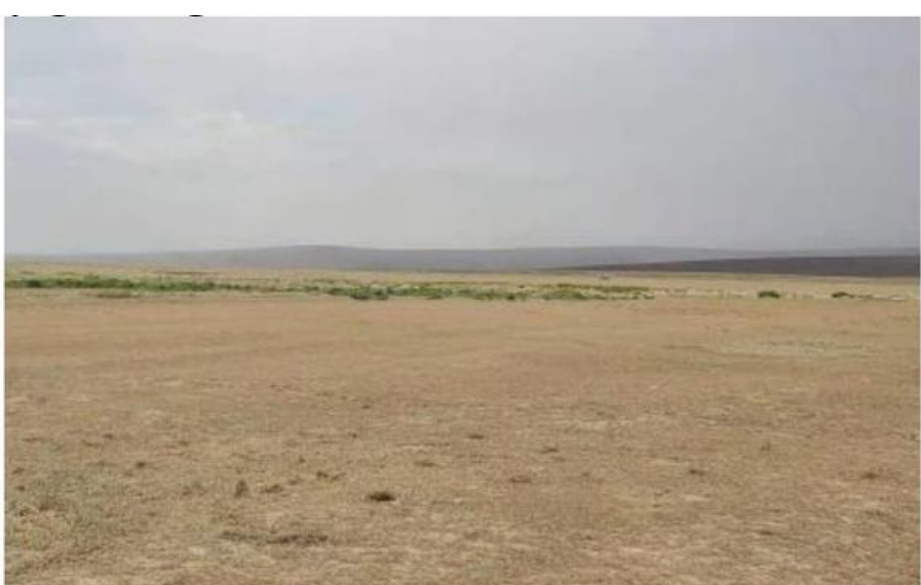

(b)Vegetation degradation

Figure 7

Eco-environmental problems in Ili No. 4 Coal Mine 


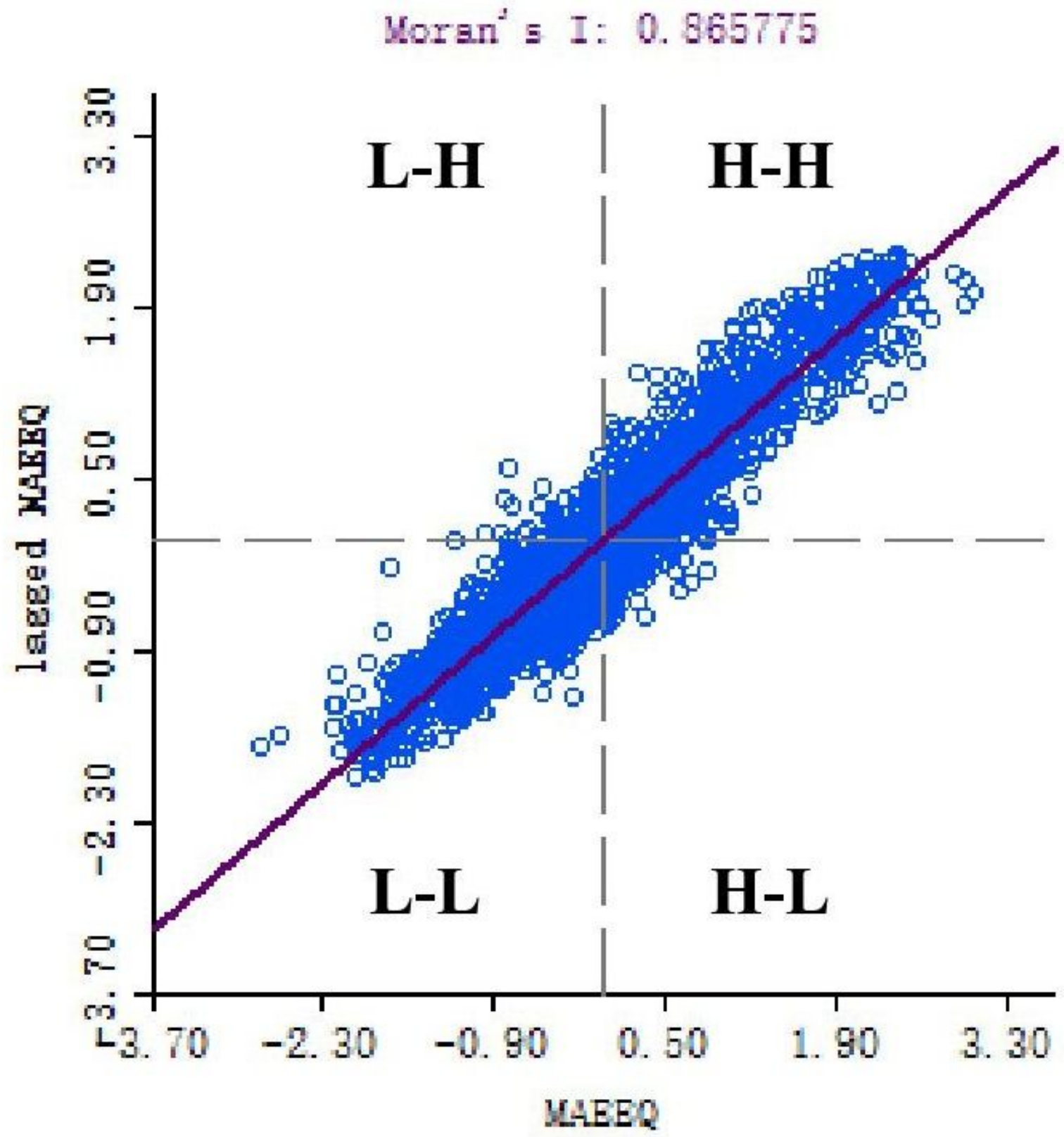

Figure 8

Moran scatter diagram of mining area eco-environmental quality (MAEEQ)

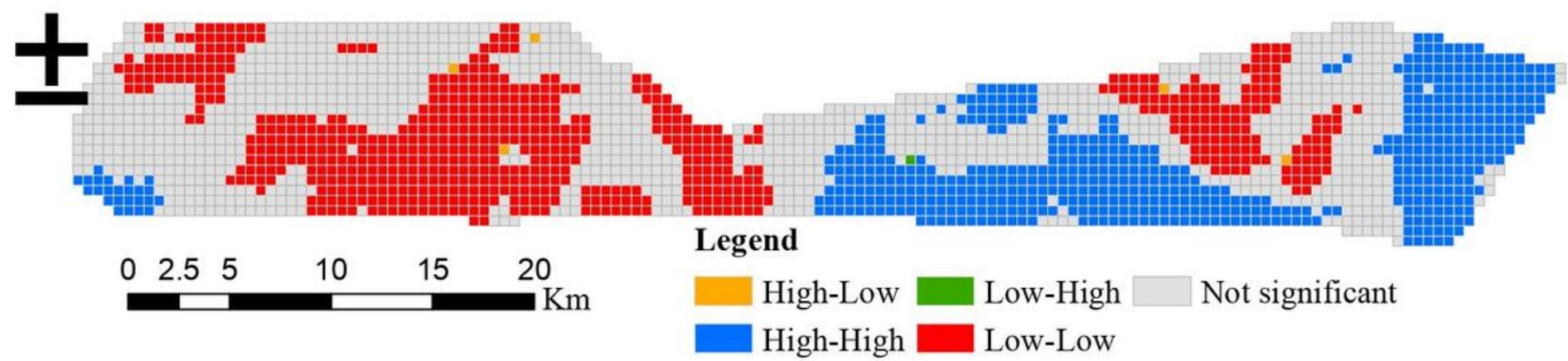

Figure 9 


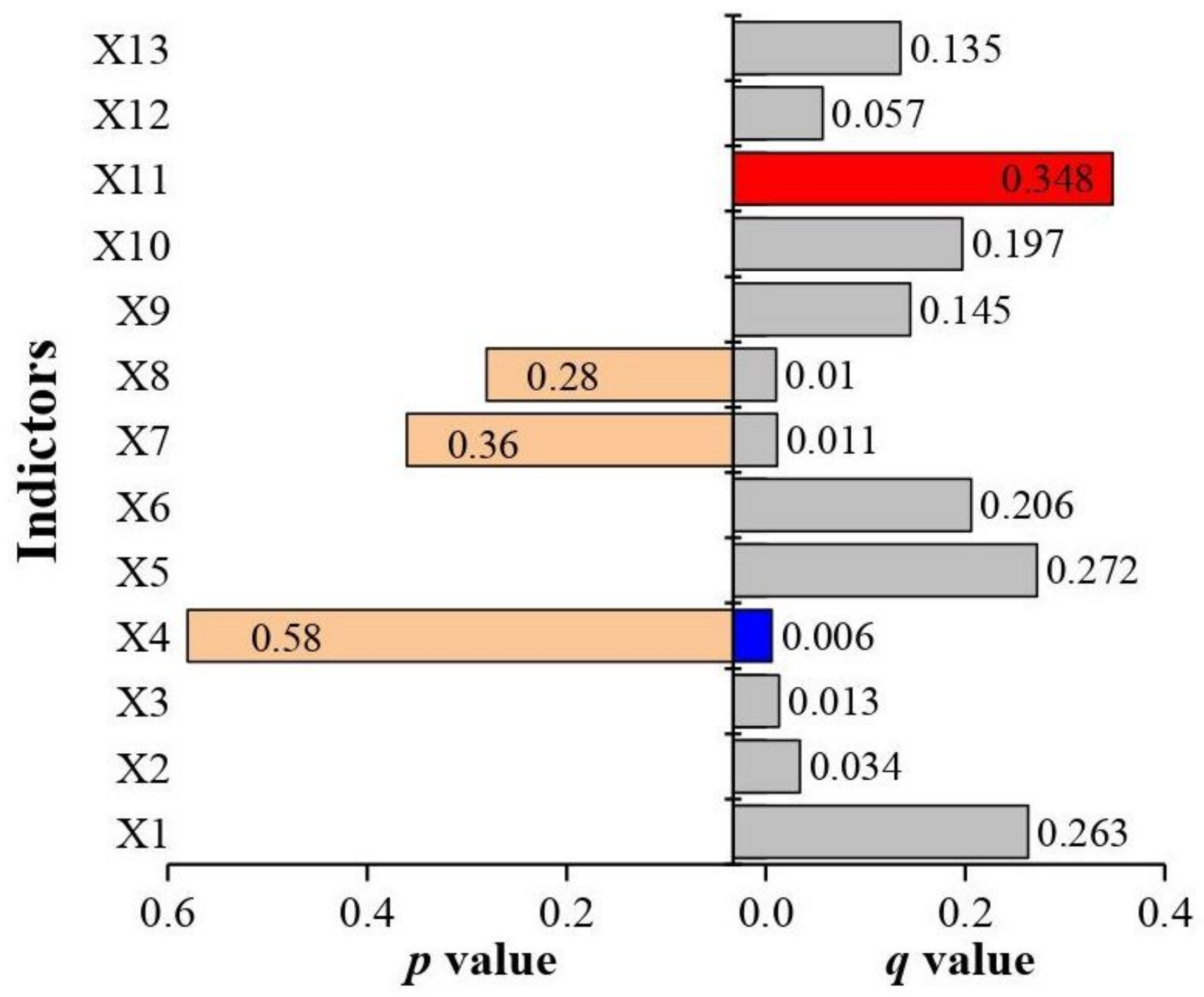

Figure 10

Detection results of various indicator factors 
$q$ value

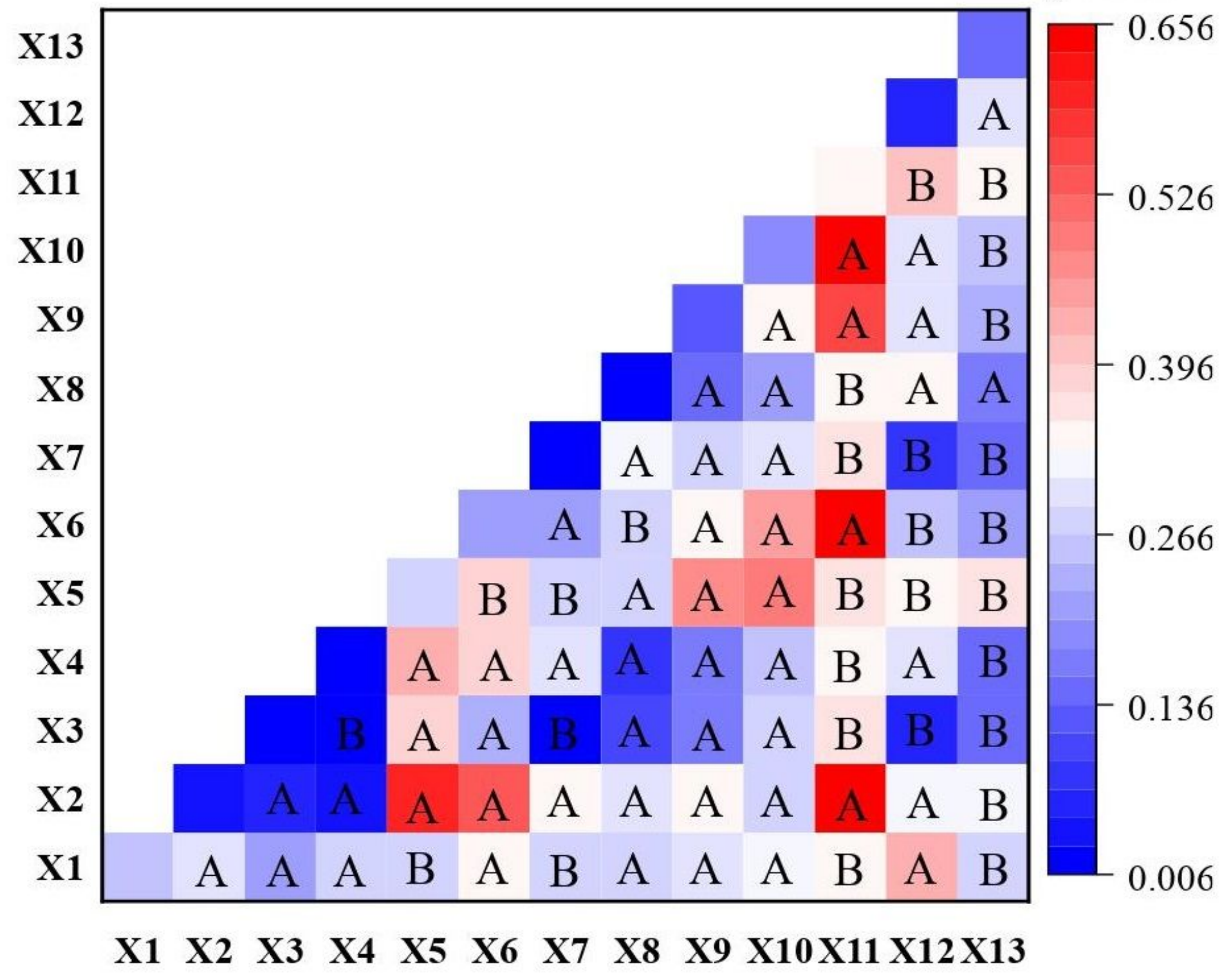

Figure 11

Detection results of indicator interaction: A refers to nonlinear enhancement; B refers to linear enhancement 


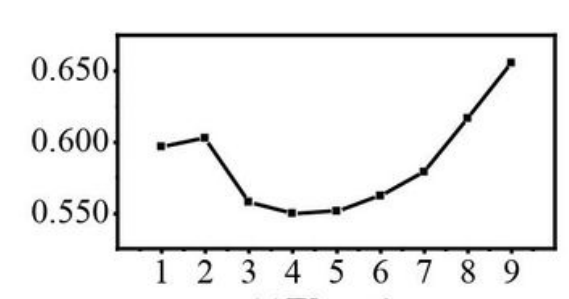

(a)Elevation

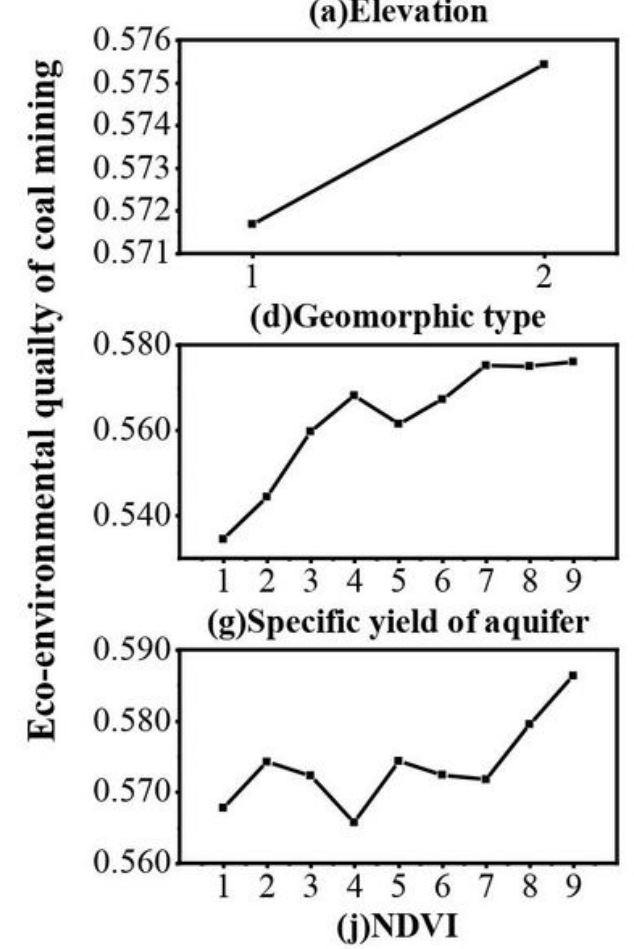

(j)NDVI

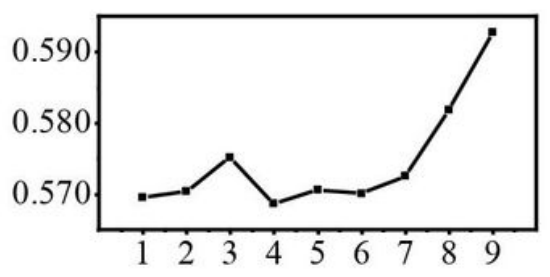

(b)Terrain slope

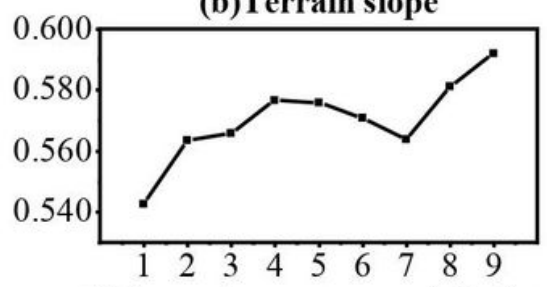

(e)Aunnal average precipitation

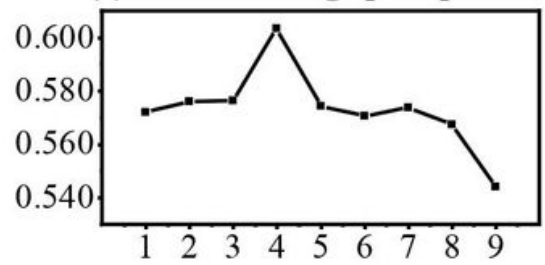

(h)River system dictance

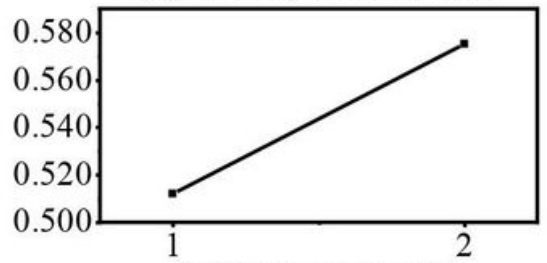

(k)Mining intensity

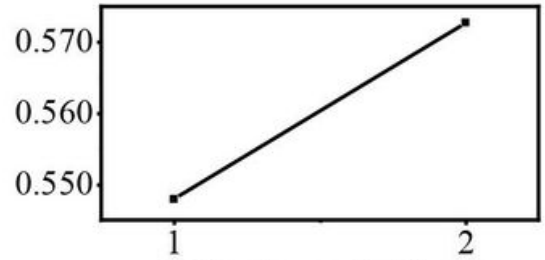

(m)Surface subcidence

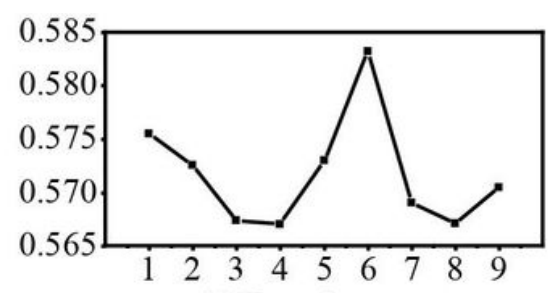

(c)Terrain aspect
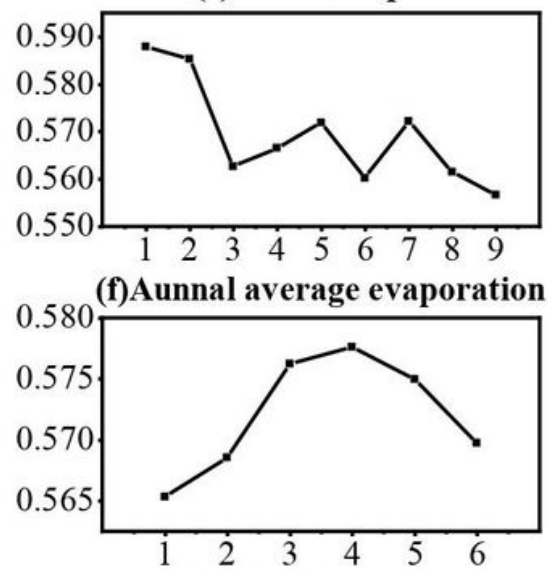

(i)Land utilisation type

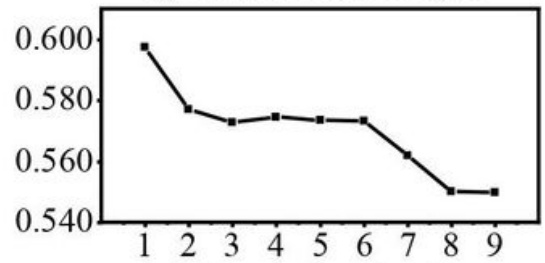

(l)Population density

Figure 12

Change of mining area eco-environmental quality with indicator grades 